IZA DP No. 10238

\title{
Does Classroom Gender Composition Affect
} School Dropout?

Bulent Anil

Duygu Guner

Tuba Toru Delibasi

Gokce Uysal

September 2016 


\title{
Does Classroom Gender Composition Affect School Dropout?
}

\author{
Bulent Anil \\ Bahcesehir University and IZA \\ Duygu Guner \\ Research Center of Public Economics, KU Leuven \\ Tuba Toru Delibasi \\ Bahcesehir University \\ Gokce Uysal \\ Bahcesehir University and IZA
}

\section{Discussion Paper No. 10238 \\ September 2016}

\author{
IZA \\ P.O. Box 7240 \\ 53072 Bonn \\ Germany \\ Phone: +49-228-3894-0 \\ Fax: +49-228-3894-180 \\ E-mail: iza@iza.org
}

\begin{abstract}
Any opinions expressed here are those of the author(s) and not those of IZA. Research published in this series may include views on policy, but the institute itself takes no institutional policy positions. The IZA research network is committed to the IZA Guiding Principles of Research Integrity.

The Institute for the Study of Labor (IZA) in Bonn is a local and virtual international research center and a place of communication between science, politics and business. IZA is an independent nonprofit organization supported by Deutsche Post Foundation. The center is associated with the University of Bonn and offers a stimulating research environment through its international network, workshops and conferences, data service, project support, research visits and doctoral program. IZA engages in (i) original and internationally competitive research in all fields of labor economics, (ii) development of policy concepts, and (iii) dissemination of research results and concepts to the interested public.
\end{abstract}

IZA Discussion Papers often represent preliminary work and are circulated to encourage discussion. Citation of such a paper should account for its provisional character. A revised version may be available directly from the author. 
IZA Discussion Paper No. 10238

September 2016

\section{ABSTRACT}

\section{Does Classroom Gender Composition Affect School Dropout?}

Measuring the gender peer effects on student achievement has recently attracted a lot of attention in the literature. Yet, the results are inconclusive. A substantial amount of research shows that having relatively more girls in a division increases the academic achievement of all students. Nevertheless, the identification of pure gender effects remains a challenge due to the fact that girls outperform boys in overall academic performance. Our study overcomes this identification problem in a setting where girls are not academically better. Using 20092010 school year data on $8^{\text {th }}$ graders in Turkey, this paper disentangles pure "academic" peer effects and "gender" peer effects. Our estimations reveal that the higher the share of females in a division, the lower the likelihood that a student drops out. One standard deviation increase in the share of females in the division decreases the likelihood of dropout by 0.3 percentage points. This result holds even though females are 9.32 percentage points more likely to drop out. These findings are robust to the inclusion of various control variables e.g. parental and academic background of the student, school and regional characteristics. We also find that the gender peer effects are prevalent in both females and males.

JEL Classification: J16, I20

Keywords: $\quad$ gender, peer effects, dropout

Corresponding author:

Bulent Anil

Bahcesehir University

Ciragan Avenue Osmanpaşa Mektebi Sokak No: 4 - 6

Besiktas

Istanbul, 34353

Turkey

E-mail: bulent.anil@eas.bau.edu.tr 


\section{Introduction}

The interaction between peers and its effect on individuals' outcomes have been studied since the Coleman Report (1966). Peer effects have been examined across a broad set of outcomes ranging from educational outcomes (e.g. test scores, dropouts) to behavioral outcomes (e.g. teenage pregnancy, drug use) (Evans et al. (1992), Gaviria and Raphael, (2001)). Even though the latter presents an interesting outlet, the literature has mainly focused on the former. Sacerdote (2011) provides an extensive summary of the literature pointing out that peer effects are particularly sizeable in primary and secondary education. These findings suggest that when peer effects are sufficiently large, a relatively less costly policy of a simple reassignment of students across sections of schools will improve student achievement considerably as noted by Hoxby (2011).

A relatively recent strand in the literature including Hoxby (2000), Whitmore (2005), Lavy and Schlosser (2011), Mora and Oreopoulos (2011), and Hill (2015) focuses on the relationship between the gender composition of peers and educational outcomes. The main goal of these studies is to separate out gender peer effects, where a major obstacle is to untie what can be called “academic peer effects” and "gender peer effects”. This task is particularly difficult when both effects work in the same direction. For example, if girls are academically better than boys and having higher a share of girls in a peer group increases the academic achievement, then identifying the gender peer effects becomes challenging.

Hoxby (2000) is the first paper to study the effects of gender composition on academic achievement. They show that girls are academically better and that having a higher share of girls in a classroom increases student achievement. They mention two distinct mechanisms: the 
higher academic ability of girls (academic peer effect) and social environment of the classroom (gender peer effect), but they do not measure them separately. Following this line, Gottfried et al. (2013) and Hill (2015) also investigate the potential effect of the gender composition of students' peers. Unlike Hill (2015), Gottfried et al. (2013) and Hoxby (2000) find significantly positive effects; nevertheless, it is not possible to conclude whether these are due to gender or academic peer effects.

Whitmore (2005) aims to identify these two channels using instruments: The average test scores of peers for the academic-peer effects and the fraction of female students for the gender-peer effects. They show that both mechanisms are significant and that the gender peer effect may be stronger than the academic peer effect. One point increase in the peers' test scores increases the student's own test scores by 0.6 points whereas being in a predominantly female classroom increases it by 1.3 point. However, these effects may be overestimated given that the set of control variables are limited.

Lavy and Schlosser (2011) benefits from a longitudinal Israeli data with a wider set of control variables to exploit the random variation across cohorts when extracting the gender peer effects. In the subjects they study, girls outperform boys considerably, thereby rendering the identification of gender peer effects and academic peer effects more difficult. Only once the authors mention a subject which girls underperform boys without specifically mentioning the subject. The authors do not discuss this finding in detail, but state that it may be due to spillover across subjects. The authors take their analysis one step further by exploring the mechanisms which the gender peer effects work. They show that a relatively higher share of girls in the 
classroom leads to a better learning environment. They also note that this amelioration in the learning environment does not stem from an improvement in students' behavior.

We attempt to address this issue in a setting where academic peer effects and gender peer effects work in opposite directions. We use a unique data set containing detailed academic and socioeconomic information on all students who are completing their $8^{\text {th }}$ grade, the last grade in compulsory education in Turkey at the time. We focus on the decision of whether to continue the $9^{\text {th }}$ grade and find that the academic peer effects are sizeable, i.e. one standard deviation increase in the academic standing of students in a class decreases the dropout probability by 4.36 percentage points, even after controlling for a wide set of socioeconomic background variables. More importantly, one percentage point increase in the share of girls in the class decreases the dropout probability by 0.3 percentage points. This result holds even though girls are 9.32 percentage points more likely to drop out. In other words, contrary to previous findings in the literature, having a higher share of girls in the classroom helps students even though girls' academic performance is relatively poorer. Like Lavy and Schlosser (2011), we also investigate the behavior channel. They show that a higher share of girls improves the learning environment and argue that this may be one of the mechanisms through which gender peer effects operate. We control directly for the learning environment as measured by the class average of the behavior scores.

One potential concern in the existing literature is that students may be choosing their peers according to some unobservable factors that may be correlated with student outcomes. The education system in Turkey allows us to overcome this obstacle as student assignments across public schools are centrally administrated by the Ministry of National Education (MONE). 
MONE also issues a directive prohibiting any ability based assignments or sorting across sections. The details are provided in Section II. Moreover, only $2.5 \%$ of students in primary schools are attending private schools. We exclude these students who are attending private institutions and thus, our analysis abstracts from school and peer choice. Additionally, our data consist of $8^{\text {th }}$ graders who are in the last year of compulsory education at the time, which further diminishes the school choice.

Our study also contributes to the literature on dropout as there are currently no studies linking the dropout decision and the gender peer effects. The detrimental effects of dropping out not only on employment and wages but also on self-reported health, welfare use, criminal records and wellbeing are well documented. Earlier studies on dropping out behavior of students find that student's preference such as lower expectation from graduation (Eckstein and Wolpin, 1999), myopic behavior (Oreopoulos, 2007), family structure (Astone and McLanahan, 1994), family income (Belley, Frenette and Lochner, 2008), parents' education and their valuation of education (Foley, Gallipoli and Green, 2014) are some factors that leads to dropout decision. Tansel (2002) uses household level data to analyze the educational attainment in Turkey and confirms that the factors established in the literature such as income, parental education, location, and migration are also valid in Turkey. Mocetti (2012) is the closest study to our work as they study the dropout decision after the completion of compulsory schooling in Italy; however, they do not analyze the gender peer effects. 


\section{Institutional Framework (The educational system in Turkey)}

Turkey has a centrally administrated education system. In 1997, compulsory education was increased to 8 years in Turkey and consequently enrolment rates of 6 to 14 year olds soared. Net enrolment rate reached $98.4 \%$ in the $2010-2011$ school year. Parallel to the increases in enrolment rates in primary education, enrolment in secondary education has also increased during this time period. Net enrolment rates increased from 37.9\% in the 1997 - 1998 school year to $69.3 \%$ in the 2010 - 2011 school year. The gross rates increased from 52.8 to $93.3 \%$. The directive 2009/52 issued by the Ministry of National Education in 2009 stated an objective to increase the gross enrolment rates in secondary education to 100 percent by the $2012-2013$ school year. An additional change put into effect in 1997 legislation dictated that all schools become mixed gender schools in compulsory education.

As for school choice, students are not allowed to choose schools in primary education. Rather, they are assigned across public schools in the district (ilçe) by the MONE. ${ }^{1}$ The allocation of resources, both in terms of infrastructure and teachers, are administrated centrally by the MONE. Unlike some systems, e.g. the US, where public schools are funded by local taxes, in Turkey, the provision of public schools does not depend on the local tax contributions. Therefore, there are no *better* neighborhoods where families pay higher taxes for *better* schools. In other words, district choice is not driven by school choice. Students in private schools constitute the only exception as they are free to choose their schools. Therefore, they are excluded from the analysis

\footnotetext{
${ }^{1}$ There were 919 districts in Turkey in 2010 and the population was approximately 75 million. The smallest district Kofçaz had 2.8 thousand residents and the largest district Çankaya had 797 thousand thousand residents.
} 
below. Note that only $2.5 \%$ of students were attending private primary schools in 2010 in Turkey.

There are two other regulations that further restrict school choice. First, MONE prohibits any sorting across divisions in a given school. In other words, students are not allowed to choose divisions, and hence class teachers. Secondly, teachers are assigned centrally to schools by a nationwide test, Public Personnel Selection Exam (PPSE).

Upon completion of the compulsory primary education, students face two options, either they are assigned to the nearest public high school or they take a nationwide Level Determination Test (Seviye Belirleme Sinavi, SBS) to apply to another high school, public or private. Note that all students who would like to continue on to high school can do so if they complete compulsory primary education. However, students who would like to attend *better* schools, take the SBS to be able to apply. Therefore, SBS scores serves as a good indicator of academic achievement for those who take it.

In primary education, students have only one class teacher in the first five years of compulsory education. In the last three years, they start to take courses from different teachers who have majored on subjects, such as mathematics, science and literature. Therefore, in $8^{\text {th }}$ grade, they face different teachers for different subjects but students do not change their division for different courses, so they stay with the same peers. All schools in Turkey use the same grading system so there is no potential grade variation across schools or provinces. 


\section{Data and descriptive statistics}

We use data from the e-School system implemented by the MONE in Turkey. The e-School system collects data on the entire population, i.e. all children at the age of compulsory education are registered in the system. The system constitutes an administrative tool to which schools and parents have access. In this system, MONE, the school administrators and teachers enter information regarding the students' academic standing such as nationwide test scores, grades, attendance, coursework, etc. Our data contains a subset of information regarding the entire population of all students finishing compulsory education during the academic year 2009-2010. Given that the focus of this paper is the transition from 8th to 9th grade, the data set consists of students who have completed 8th grade successfully.

The data include family and individual characteristics as well as academic information. We observe extensive socioeconomic, demographic, academic and parental information for each student in our dataset. Information on number of siblings, age, education, labor market status and parental income are collected from the parents whereas information on academic background, such as grades, attendance, end of year grades, are collected from teachers throughout the school year. Information on school resources such as type, number of science labs and other facilities are provided by the headmasters of the school. Table 1 summarizes the descriptive statistics of our sample. $^{2}$

\footnotetext{
${ }^{2}$ Private schools are excluded from our sample.
} 
Table 1 Descriptive Statistics

\begin{tabular}{|c|c|c|}
\hline Variable & Mean & Std. Dev. \\
\hline School Dropout & 0.20 & 0.40 \\
\hline Share of Females in division & 0.48 & 0.10 \\
\hline Class Environment & 4.28 & 0.40 \\
\hline Division Average of SBS Score & 293.76 & 43.64 \\
\hline School Average of SBS score & 295.66 & 34.00 \\
\hline Female & 0.48 & 0.50 \\
\hline Age & 15.14 & 0.64 \\
\hline Number of siblings & 2.42 & 1.93 \\
\hline Mother's Age & 41.09 & 5.70 \\
\hline Father's Age & 44.84 & 5.68 \\
\hline Mother Primary & 0.19 & 0.39 \\
\hline Mother Middle School & 0.69 & 0.46 \\
\hline Mother High School & 0.09 & 0.29 \\
\hline Mother Higher Educ. & 0.03 & 0.16 \\
\hline Father Primary & 0.06 & 0.24 \\
\hline Father Middle School & 0.69 & 0.46 \\
\hline Father High School & 0.17 & 0.38 \\
\hline Father Higher Educ. & 0.07 & 0.26 \\
\hline Father works & 0.94 & 0.24 \\
\hline Mother works & 0.20 & 0.40 \\
\hline Low income & 0.04 & 0.20 \\
\hline Lower middle income & 0.26 & 0.44 \\
\hline Middle Income & 0.46 & 0.50 \\
\hline Upper middle income & 0.23 & 0.42 \\
\hline High income & 0.02 & 0.13 \\
\hline Conditional Cash Transfer & 0.05 & 0.22 \\
\hline GPA (SD) & -0.02 & 0.98 \\
\hline Maths (SD) & -0.03 & 0.97 \\
\hline Science (SD) & -0.03 & 0.97 \\
\hline Turkish (SD) & -0.02 & 0.98 \\
\hline Student taken SBS & 0.86 & 0.35 \\
\hline Dorm & 0.03 & 0.18 \\
\hline Public & 0.97 & 0.18 \\
\hline Student per Teacher & 26.52 & 8.36 \\
\hline Share of permanent teachers & 0.85 & 0.15 \\
\hline Science Lab & 0.83 & 0.37 \\
\hline Multipurpose Lab & 0.56 & 0.50 \\
\hline Divison size & 31.29 & 9.28 \\
\hline Village & 0.10 & 0.30 \\
\hline County & 0.09 & 0.29 \\
\hline Urban & 0.81 & 0.39 \\
\hline
\end{tabular}


After finishing compulsory education, students may choose to leave school or continue with a non-compulsory high school education. In our sample, around 20 percent of students choose to drop out.

Let us concentrate on the variable that we use to identify gender peer effects, i.e., the average share of females in a division. Error! Not a valid bookmark self-reference. demonstrates the distribution. The average in the sample is 47 percent and standard deviation is 10 percent. $^{3}$

Figure 1 A Histogram of the Share of Females

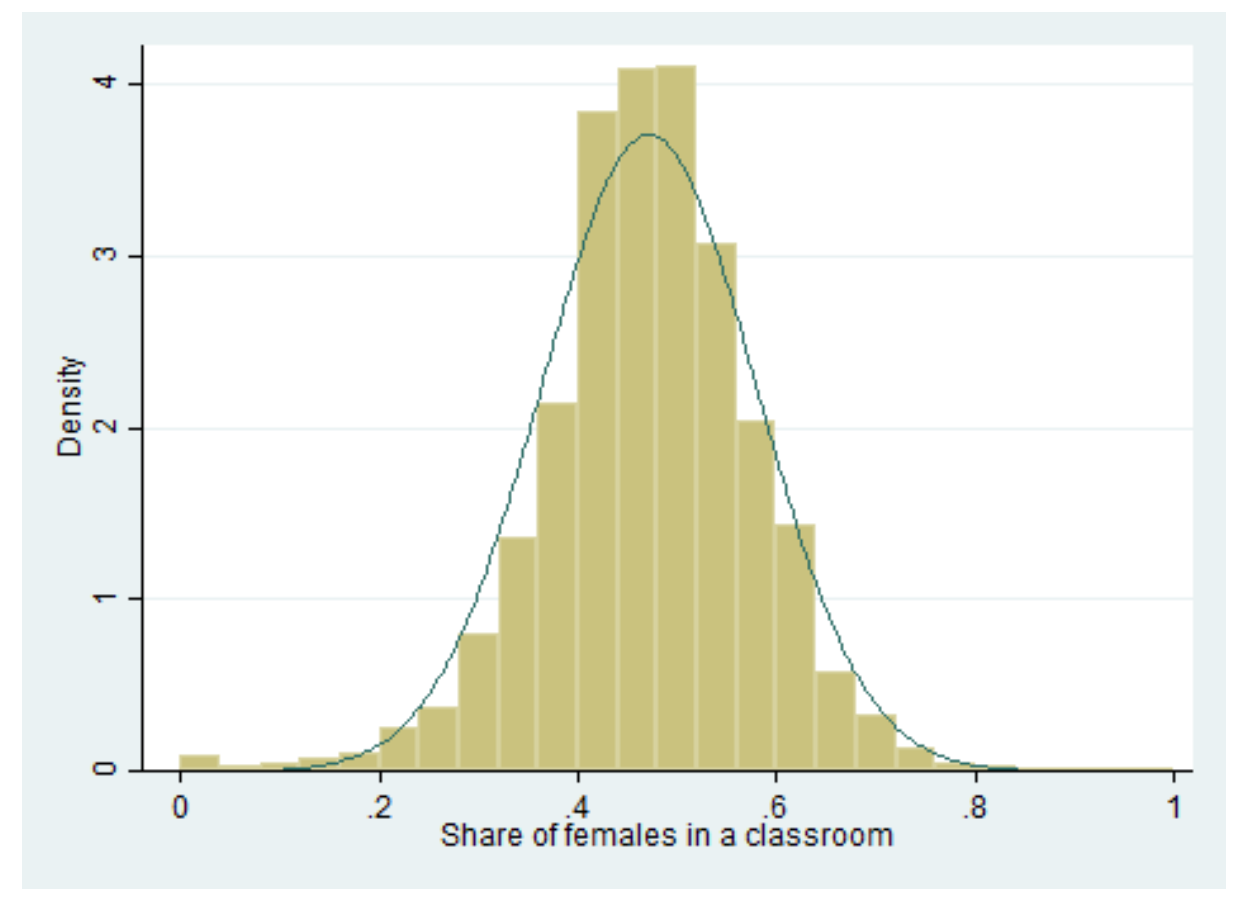

${ }^{3}$ Although it is not officially allowed, there are 1873 students in single sex divisions across Turkey, out of more than a million $8^{\text {th }}$ graders. As shown in Figure 2, both male only and female only schools have lower SBS scores on average compared to gender mixed schools. 
We construct two variables to measure academic peer effects: Division average of SBS scores and school average of SBS scores. As explained above SBS is a nationwide test measuring the academic aptitude and e-School data contains information on whether the student took the test and their scores. Over 85 percent of students took the exam in our sample. In addition, the data provides the grade point average (GPA) records of students, their grades from math, science and Turkish. We normalize each individual score for each subject at the division level. Hence, grades from different evaluations (exam, instructor, etc.) can be analyzed on a common scale.

When we explore the academic achievement by gender, our data show that girls are more likely to drop out. If academic peer effects are sizeable, this may potentially be due to a discriminatory assignment that places girls in divisions with academically poor peers. In that case, girls will be more likely to drop out because of the academic peer effects. If there is such a discriminatory assignment across divisions, then we would expect academic performance in a division to be highly correlated with the share of females in that division. Figure 2 depicts the share of females against the division average of SBS scores. Evidently, this figure does not reveal any strong relationship between the two measures, i.e. the correlation between these two variables is 0.21 . Clearly, this is a descriptive result on which we will elaborate below. 
Figure 2 Share of females in a division vs. division average of SBS score

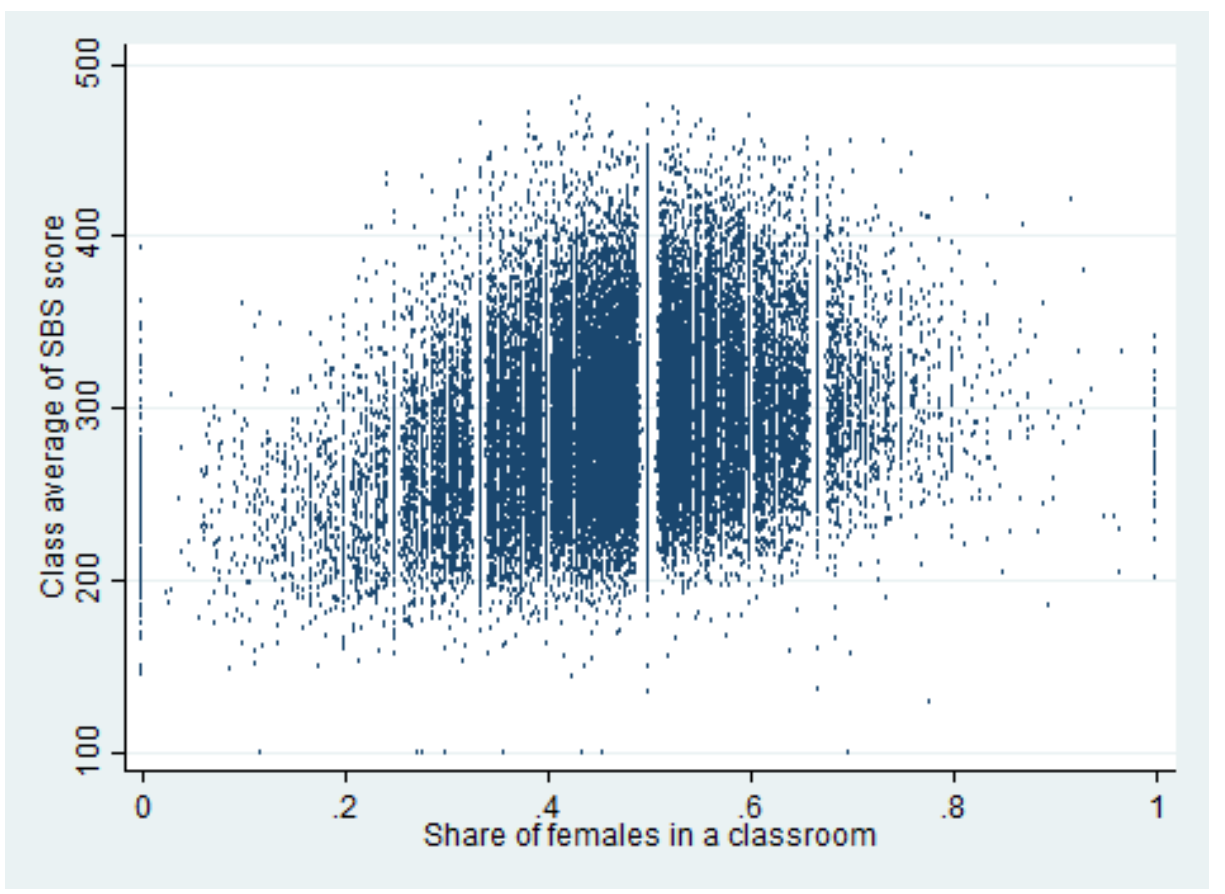

To explore potential channels through which the gender peer effects may operate, we include a variable that reflects the learning environment in a division, i.e. the average behavior grade of students in a division. As discussed by Lavy and Scholesser (2011), girls may contribute to a better learning environment, hence allowing all students in a division to do better academically. If so, controlling for the learning environment in a division will allow us to separate the gender peer effects from any potential effects of the learning environment as measured by the average behavior grades of students in that division.

Unfortunately, 44 percent of the students had missing information on at least one of our variables. (See Table 1-A in Appendix) Ignoring missing data (e.g., listwise deletion and pairwise deletion) may introduce a bias in the data in addition to obvious loss of information. 
This occurs if the complete observations are not a random sample of the population data. Rubin (1976) develops a classification for missing data mechanisms: Missing completely at Random (MCAR), missing at random (MAR) and missing not at random (MNAR). The existing mechanism should be determined in order to choose the best method to deal with missing data. ${ }^{4}$ We test the missing data and find some evidence for MAR. Peugh and Enders (2004) states that multiple imputation and maximum likelihood methods have superiority in terms of efficiency and unbiasness over traditional methods such as listwise and pairwise deletion if the missing data is either MCAR or MAR. ${ }^{5}$ Multiple imputations require the multivariate normality assumption. Given that we have several discrete variables in the missing data, we implement multiple imputations following Graham and Schafer (1999) who present some evidence that multiple imputations performs well under fairly substantial violations of normality. Moreover, multiple imputation produces unbiased parameter estimates when data are MAR (or MCAR). In our study, all analysis are performed using imputed data.

\section{Model Specification}

Using one cohort of students that completed compulsory education in the education year 20092010, we estimate the effect of the gender peer effects, as measured by the share of females in a division, on the academic achievement of a student in that division, as measured by the dropout while controlling for personal characteristics (age, age squared, number of siblings), parental

\footnotetext{
${ }^{4}$ For detailed discussion, see Muthen et al., 1987, Enders, 2003, Graham and Schafer, 1999, Peugh and Enders, 2004.

${ }^{5}$ See Peugh and Enders (2004). They provide an overview of missing-data theory and methods.
} 
background (parents' age, education, labor market status, income, conditional cash transfer status), academic background (student's GPA, math, science and Turkish grades, a dummy for taking the SBS), school characteristics (dormitory, student to teacher ratio, share of permanent teachers, science lab, multi-purpose room) and location (province dummies, urban/rural status).

There are some econometric challenges in measuring gender peer effects on the academic achievement. First of all, omitted variables may cause biases in the econometric analysis. On one hand, the data that we use are rich enough to allow extensive control variables reflecting various family background characteristics. On the other hand, data lacks important information on some key variables that affect educational outcomes. One such variable is teacher quality. Even though there is no direct measure of teacher quality, we include the share of teachers on a permanent contract as a proxy. Another potential explanatory factor is the gender of the teacher. There is some evidence suggesting that gender of teachers may have sizeable effects (Muralidharan and Sheth, 2016; Antecol et al., 2015, Winters et al., 2013). Again, there is no information on teachers, including their gender. However, since $8^{\text {th }}$ grade curriculum includes a variety of subjects taught by different teachers, students potentially face teachers of different genders, easing such concerns.

A second major issue in identification is selection bias. One potential bias may stem from students choosing to stay in school, another from students choosing their schools, yet another from students choosing their divisions. In our case, attending $8^{\text {th }}$ grade is compulsory; therefore, we have entire $8^{\text {th }}$ graders, alleviating the first concern. Furthermore, the current institutional framework in Turkey diminishes the second concern as it assigns students to the nearest school and location choices of households are independent of school choice. Nevertheless, some schools 
in some locations may be academically better, and students attending these schools may benefit from academic peer effects. To address this issue, we include a school-wide variable that measures the school average of SBS scores to control for the variation between schools.

Third, selection into different divisions may still pose an identification problem, i.e., the assignment of students across divisions may depend on academic achievement. Again, the institutional framework in Turkey dissipates some of these concerns. The regulations of the Ministry of National Education clearly prohibit non-random assignment across divisions. MONE frequently sends memoranda to all schools indicating that schools must avoid preferential treatment of students, and emphasizing the importance of providing equal opportunities. The memoranda clearly state that assignments across divisions should not depend on race, religion, gender and academic success of students. How MONE enforces these memoranda is not clear. Therefore, to rule out the possibility of non-random assignment across divisions, we check whether there are statistical differences in taking the SBS test and in SBS scores. Even though significant statistical differences across divisions exist in a limited number of settings, systematic practices are not observed. Still, we include the division average of SBS scores in the econometric analysis to control for the variation between divisions.

\section{Estimations}

The results from logit regression models are presented in Table 2. In the first model, we present the results from a baseline model where we concentrate on the gender peer effects while controlling for a wide range of background variables. In the second model, we include the control variable for the class environment, as measured by the average behavior grade of all 
students in a classroom. The third column presents the average marginal effects of Model 2. The last two columns provide coefficients from separate models for males and females. Note that all models are run on the entire data set where the missing observations are imputed as explained above.

Table 2 Estimation Results

\begin{tabular}{|c|c|c|c|c|c|}
\hline & $\begin{array}{l}\text { Model } 1 \\
\text { (I) }\end{array}$ & $\begin{array}{c}\text { Model } 2 \\
\text { (II) }\end{array}$ & $\begin{array}{l}\text { AME } \\
\text { (III) }\end{array}$ & $\begin{array}{c}\text { Female } \\
\text { (IV) }\end{array}$ & $\begin{array}{l}\text { Male } \\
(\mathrm{V})\end{array}$ \\
\hline Share of females in class & $\begin{array}{c}-0.427 * * * \\
(0.0609)\end{array}$ & $\begin{array}{c}-0.312 * * * \\
(0.0610)\end{array}$ & $0.0281^{* * *}$ & $\begin{array}{c}-0.160 * \\
(0.0817)\end{array}$ & $\begin{array}{c}-0.766 * * * \\
(0.0785)\end{array}$ \\
\hline Class environment & & $\begin{array}{c}-0.388 * * * \\
(0.0223)\end{array}$ & $0.0350 * * *$ & $\begin{array}{c}-0.425 * * * \\
(0.0292)\end{array}$ & $\begin{array}{c}-0.371^{* * *} \\
(0.0276)\end{array}$ \\
\hline Class average of SBS scores & $\begin{array}{l}-0.0126 * * * \\
(0.000215)\end{array}$ & $\begin{array}{l}-0.0107 * * * \\
(0.000243)\end{array}$ & $\begin{array}{c}- \\
0.0010^{* * *}\end{array}$ & $\begin{array}{l}-0.0121^{* * *} \\
(0.000320)\end{array}$ & $\begin{array}{c}- \\
0.00918 * * * \\
(0.000326)\end{array}$ \\
\hline School average of SBS & - & - & - & - & - \\
\hline scores & $\begin{array}{c}0.00412 * * * \\
(0.000326)\end{array}$ & $\begin{array}{c}0.00382 * * * \\
(0.000326)\end{array}$ & $0.0003 * * *$ & $\begin{array}{c}0.00432^{* * *} \\
(0.000419)\end{array}$ & $\begin{array}{c}0.00369 * * * \\
(0.000416)\end{array}$ \\
\hline Female & $\begin{array}{l}1.024 * * * \\
(0.0114)\end{array}$ & $\begin{array}{l}1.033 * * * \\
(0.0115)\end{array}$ & $0.0932 * * *$ & & \\
\hline Personal characteristics & $\checkmark$ & $\checkmark$ & & $\checkmark$ & $\checkmark$ \\
\hline Parental background & $\checkmark$ & $\checkmark$ & & $\checkmark$ & $\checkmark$ \\
\hline Academic background & $\checkmark$ & $\checkmark$ & & $\checkmark$ & $\checkmark$ \\
\hline School characteristics & $\checkmark$ & $\checkmark$ & & $\checkmark$ & $\checkmark$ \\
\hline Province & $\checkmark$ & $\checkmark$ & & $\checkmark$ & $\checkmark$ \\
\hline Constant & $\begin{array}{c}15.89 * * * \\
(0.847)\end{array}$ & $\begin{array}{c}16.79 * * * \\
(0.847)\end{array}$ & & $\begin{array}{c}17.70^{* * *} \\
(1.157)\end{array}$ & $\begin{array}{c}16.14^{* * *} \\
(1.158)\end{array}$ \\
\hline Nb of observations & 1151642 & 1151642 & & 542809 & 608833 \\
\hline
\end{tabular}

Standard errors in parentheses

$* * * \mathrm{p}<0.01, * * \mathrm{p}<0.05, * \mathrm{p}<0.1$

Personal characteristics: age, age squared, number of siblings. Parental background: parents' age, education, labor market status, income, conditional cash transfer status. Academic background: student's GPA, math, science and Turkish grades, a dummy for taking the SBS. School characteristics: dormitory, student to teacher ratio, share of permanent teachers, science lab, multi-purpose room. Province: province dummies, urban/rural status. 
The coefficients in Model 1 and Model 2 show that the share of females in a division is an important factor in student achievement. Students who have a higher share of female peers have lower dropout probabilities. This result holds even when we control for academic peer effects at the division level and at the school level. In Model 2, we include the class environment variable, aiming to separate the gender peer effects from the potential effects of a better learning environment. The results indicate that the gender of a student's peers have an effect over and above a better learning environment.

Let us turn to the column III where we present the average marginal effects. Unlike countries such as US and Canada, our results also reveal that girls are more likely to drop out in Turkey. The likelihood of dropout is 9.32 percentage points higher for girls than boys, which is a stark divergence from the literature on dropout. In a setting where the academic achievement of girls is better than boys, the identification of gender peer effects difficult since students in divisions with higher shares of females benefit from academic peer effects as well as gender peer effects. In our study, girls are more likely to drop out, the coefficient being -0.312 . That is, one standard deviation increase in the share of girls in a division leads to 0.3 percentage point decrease in the likelihood of dropout of a student in that division. In other words, the gender peer effects and academic peer effects are not working in the same direction which allows us to disentangle gender peer effects and academic peer effects. If we were only observing academic peer effects, we would have found a positive relationship between the share of girls and the probability of dropout. We find the opposite. Note that we control extensively for the academic performance of the students by including variables that reflect students' relative standing in a division, e.g. their standardized scores on subjects like math, science and Turkish. The academic peer effects, as 
measured by the division average and the school average of SBS scores, seem to be smaller in size but still highly significant: the coefficients are respectively -0.107 and -0.00382 . These coefficients imply that one standard deviation increase in the division average of SBS scores decreases dropout probability by 4.36 percentage points, and one standard deviation increase in the school average by 1.02 . The class environment, as measured by the division average of behavior grades, is an important and significant determinant of dropout. One standard deviation increase in class environment decreases the likelihood of dropout by 1.4 percentage points. Lavy and Schlosser (2011) argue that class environment would be one of the mechanisms in better learning process and they show that higher share of females in a class improves the class environment. Hence, we included a control variable for the class environment (i.e. the division average of behavior grades) in our estimations and we still find a significant effect for share of females.

The use of average SBS scores also enables us to address the selection bias caused by potential non-random assignments to divisions. In 2009-2010 school year, enrolment in $8^{\text {th }}$ grade was compulsory, but not the attendance, which could be a strong indicator of dropout behavior. School administrators may choose to group non-attending students in certain divisions creating academically poor divisions in which we might observe higher shares of females, given that females have a higher probability to drop out. Note that in that case, we would expect students in classes with a higher share of females to have higher dropout probabilities. In our case, the opposite result hold, i.e. even though females are more likely to drop out, students in divisions with higher shares of females are less likely to drop out. Then, the identification of the underlying mechanism of dropping out, whether it is gender peer effects or academic peer 
effects, would be difficult. The inclusion of the average SBS scores of each division helps us to disentangle these two effects.

Clearly, the regression results show that academic background has an important effect on the probability of dropout. As explained before, we include the GPA as well as math, science and Turkish grades in the model. Even though the scale of grades are the same across divisions and schools, these grades may still not be comparable across schools, even across divisions in a given school as these grades are based on exams that are carried out at the section level, different teachers are grading the exams. Therefore, we normalize the student grades at the division level. This allows us to at least compare the grades of the student with other students in a given division and hence use the academic achievement of the student relative to other students in their section. In other words, we concentrate on the variation within a division, rather than across divisions. The results show that students with relatively higher grades are more likely to continue high school education after completing their compulsory education. Not surprisingly, the students who take the SBS exam are less likely to drop out since taking this test shows a clear intention of transition to secondary education.

One could argue that boys and girls have different production functions and if so, gender peer effects may work through inherently different mechanisms therefore the mechanism how gender peer effects work would be completely different. In column IV and V, we estimated Model 2 specification for these two subgroups. Our results indicate that the gender peers effects are slightly different for boys and girls suggesting that male students benefit more than female students from being in a diverse gender in a division. 
The rest of the results are in line with the previous literature. We observe that dropout probabilities increase with the number of children in a family consistent with the quantity quality trade-off. Parental education has the expected effect, i.e. our results confirm a negative relationship between parental education and the probability of dropout. We also find that parental employment decreases dropout probabilities even when self-reported family income is included in the regressions. Lastly, we have province and urban/rural status dummies in the regressions, in which the reference category is attending a school in an urban area. The estimated coefficients show that attending schools in counties and villages increase the probability that a student will drop out.

\section{Conclusion}

This paper analyzes the impact of gender composition in a division on the academic achievement of the students in that division. Particularly, we examine the effect of the share of females in a division on the students' probability of dropout. Even though it has been studied before, the identification of gender peer effects is rather challenging when both gender peer effects and academic peer effects work in the same direction. Especially, the literature on developed countries encounters such a challenge since they have lower dropout rates for girls. In this study, we exploit a rich data set that contains demographic, parental and academic information which allows us to separate the gender peer effects from academic peer effects. Our findings reveal that, contrary to studies on developed countries, girls have a higher dropout rate in Turkey even after controlling for parental and academic background variables. The identification of the gender peer effects is decisive since the study is conducted in a setting where gender peer effects and academic peer effects are working in opposing direction. In other words, if girls have higher 
dropout probabilities, students in divisions with relatively high share of girls would have higher dropout probabilities, according to academic peer effects. Nevertheless, we observe a negative impact of the share of females on probability dropout of the student in that division.

Some potential biases such as omitted variable bias or selection biases could affect the identification of gender peer effects. Our study overcomes these potential biases by extensively controlling for parental information, which is a proxy for socioeconomic status of the families; division average of SBS scores and school average of SBS scores, controls for the academic performances of peers; and provinces, a control for the regional characteristics. Our results are in line with the existing literature, i.e. parental education, parental employment status and students' academic performance have an effect on the dropping out decision of students. Again in line with the literature, we find a negative relationship between school resources and the probability of dropout. Our results are robust when the analysis is repeated for males or females.

Our results contribute to the literature in many ways: First, we use data pertaining to the last year of compulsory schooling; therefore, all students must be enrolled in a school. In other words, there is no selection into being in education. Second, the data allows us to control extensively for demographic, parental, school and regional characteristics to identify the gender peer effects from other confounding effects. Third, we benefit from the institutional settings of educational system in Turkey where students stay with the same peers during a class year so that the peer effects they are exposed to are constant. Furthermore, students are assigned to schools by a centrally administrated system and across divisions by the school, which is directed to restrain from sorting by the Ministry of National Education. Hence, students and families can choose neither schools nor divisions. Finally, contrary to earlier literature, the gender peer effect and 
academic peer effect work in opposing directions in Turkey which allows us to disentangle gender peer effects from academic peer effects.

\section{REFERENCE}

Antecol, H., Eren, O., \& Ozbeklik, S. (2015). The Effect of Teacher Gender on Student Achievement in Primary School. Journal Of Labor Economics, 33(1), 63-89.

Astone, N. M., \& McLanahan, S. S. (1994). Family structure, residential mobility, and school dropout: A research note. Demography, 31(4), 575-584.

Belley, P., Frenette, M., \& Lochner, L. (2008). Educational Attainment by Parental Income: A Canada-US Comparison. Unpublished. Department of Economics, University of Western Ontario.

Eckstein, Z., \& Wolpin, K. I. (1999). Why youths drop out of high school: The impact of preferences, opportunities, and abilities. Econometrica, 67(6), 1295-1339.

Enders, C. K. (2003). Using the EM algorithm to estimate coefficient alpha for scales with item level missing data. Psychological Methods, 8, 322-337.

Evans, W. N., Oates, W. E., \& Schwab, R. M. (1992). Measuring peer group effects: A study of teenage behavior. Journal of Political Economy, 966-991.

Foley, K., Gallipoli, G., \& Green, D. A. (2014). Ability, parental valuation of education, and the high school dropout decision. Journal of Human Resources, 49(4), 906-944.

Gaviria, A., \& Raphael, S. (2001). School-based peer effects and juvenile behavior. Review of Economics and Statistics, 83(2), 257-268.

Gottfried, M. A., \& Graves, J. (2014). Peer Effects and Policy: The Relationship between Classroom Gender Composition and Student Achievement in Early Elementary School. The BE Journal of Economic Analysis \& Policy, 14(3), 937-977.

Graham, J. W., \& Schafer, J. L. (1999). On the performance of multiple imputation formultivariate data with small sample size. In Rick H. Hoyle (Ed.), Statistical strategies for small sample research (pp. 1-29). Thousand Oaks, CA: Sage. 
Hill, A. J. (2015). The girl next door: The effect of opposite gender friends on high school achievement. American Economic Journal: Applied Economics, 7(3), 147-177.

Hoxby, C. M. (2000). The Effects of Class Size on Student Achievement: New Evidence from Population Variation. Quarterly Journal of Economics, 1239-1285

Lavy, V., \& Schlosser, A. (2011). Mechanisms and impacts of gender peer effects at school. American Economic Journal: Applied Economics, 1-33.

Mocetti, S. (2012). Educational choices and the selection process: before and after compulsory schooling. Education Economics, 20(2), 189-209.

Mora, T., \& Oreopoulos, P. (2011). Peer effects on high school aspirations: Evidence from a sample of close and not-so-close friends. Economics of Education Review, 30(4), 575-581.

Muralidharan, K., \& Sheth, K. (2016). Bridging Education Gender Gaps in Developing Countries: The Role of Female Teachers. Journal Of Human Resources, 51(2), 269-297.

Muthén, B., Kaplan, D., \& Hollis, M. (1987). On structural equation modeling with data that are not missing completely at random. Psychometrika, 52(3), 431-462.

Oreopoulos, P. (2007). Do dropouts drop out too soon? Wealth, health and happiness from compulsory schooling. Journal of public Economics, 91(11), 2213-2229.

Peugh, J. L., \& Enders, C. K. (2004). Missing data in educational research: A review of reporting practices and suggestions for improvement. Review of educational research, 74(4), 525-556.

Rubin, D. B. (1976). Inference and missing data. Biometrika (63), 581-592.

Tansel, A. (2002). Determinants of school attainment of boys and girls in Turkey: individual, household and community factors. Economics of Education Review, 21(5), 455-470.

Whitmore, D. (2005). Resource and peer impacts on girls' academic achievement: Evidence from a randomized experiment. American Economic Review, 199-203.

Winters, M. A., Haight, R. C., Swaim, T. T., \& Pickering, K. A. (2013). The Effect of SameGender Teacher Assignment on Student Achievement in the Elementary and Secondary Grades: Evidence from Panel Data. Economics of Education Review, 3469-75. 
Appendix

Table 1-A Missing Data

\begin{tabular}{lcc} 
Variable & N & $\mathbf{N}^{*}$ \\
\hline School Dropout & 1151642 & 0 \\
Share of Females in division & 1151642 & 0 \\
Class Environment & 1151488 & 154 \\
Division Average of SBS Score & 1150628 & 1,014 \\
School Average of SBS score & 1151387 & 255 \\
Female & 1151642 & 0 \\
Age & 1151641 & 1 \\
Number of siblings & 1151642 & 0 \\
Mother's Age & 1139925 & 11,717 \\
Father's Age & 1151642 & 0 \\
Mother Education & 745441 & 406201 \\
Father Education & 754916 & 396726 \\
Father works & 746134 & 405508 \\
Mother works & 758356 & 393286 \\
Family Income & 977499 & 174143 \\
Conditional Cash Transfer & 1151642 & 0 \\
GPA (SD) & 1146301 & 5341 \\
Maths (SD) & 1151008 & 634 \\
Science (SD) & 1150739 & 903 \\
Turkish (SD) & 1150736 & 906 \\
Student taken SBS & 1151642 & 0 \\
Dorm & 1151642 & 0 \\
Public & 1151642 & 0 \\
Student per Teacher & 1151642 & 0 \\
Share of permanent teachers & 1151375 & 267 \\
Science Lab & 1151642 & 0 \\
Multipurpose Lab & 1151642 & 0 \\
Division size & 1151642 & 0 \\
Village & 1151642 & 0 \\
County & 1151642 & 0 \\
Urban & 1151642 & 0 \\
\hline N number of observations, N* means number of missing observations \\
\hline
\end{tabular}

